\title{
TIME SERIES MODELING OF MONTHLY RAINFALL IN ARID AREAS: CASE STUDY FOR SAUDI ARABIA
}

\author{
Nidhal Saada \\ Department of Environmental Engineering, Om Al Qura University, Al-Lith, Kingdom of Saudi Arabia
}

Received 2014-04-09; Revised 2014-04-11; Accepted 2014-05-03

\begin{abstract}
Stochastic techniques are essential in planning and management of water resources systems especially in arid and semi-arid areas where water is scarce. The forecasting of future events requires identifying proper stochastic models to be used in this process. For this purpose, a Periodic ARMA (PARMA) model and a temporal disaggregation models were used in this study to investigate weather they are appropriate for modeling the monthly rainfall data in Saudi Arabia. Results showed PARMA and temporal disaggregation models performed well in modeling the monthly rainfalls in Saudi Arabia. These models were able to preserve the basic seasonal statistics of the observed data well as preserving the seasonal correlation structure observed in the historical data. However, the PARMA model did not perform well at the annual level. In contrast, the disaggregation model performed well in preserving the correlation structure of the historical data at the annual level. Thus, these models can be used in modeling and forecasting of monthly rainfall in Arid and semi-arid areas.
\end{abstract}

Key words: Stochastic Analysis, Rainfall Modeling, PARMA, Disaggregation

\section{INTRODUCTION}

Stochastic modeling of hydrologic time series has been widely used for planning and management of water resources systems (Fortin et al., 2004). Stochastic models are used in operational hydrology to generate synthetic time series which exhibit similar statistical characteristics as the observed data. Stationary (Salas et al., 1995). Auto Regressive Moving Average (ARMA) models have been widely used in stochastic hydrology to model annual time series where the mean, variance and the correlation structure do not depend on time (Kim, 2012).

Sampson et al. (2013) used a seasonal ARIMA model to model the monthly rainfall amounts for the Navrongo meteorological service station from the period January, 1980 to December, 2010 and concluded that the model was adequate. Naill and Momani (2009) used time series analysis to model monthly rainfall data at Amman Airport Station in Jordan. A seasonal ARIMA model was used in that study. However, it was concluded that the model is incapable of predicting the exact monthly rainfalls.
Seasonal basic statistics such as the mean and variance may be reproduced by ARIMA models fitted to the seasonal data after filtering out the seasonality in the data. However, in this case, these models are usually unable to capture the seasonal correlation structures that are exhibited by a hydrologic time series. Thus, Periodic (seasonal) versions of ARMA models (PARMA) have been suggested and are widely used to model seasonal hydrologic time series (Shao et al., 2009). These models have been found capable of preserving the basic seasonal statistics as well as the seasonal correlation structure (Salas et al., 1982).

Disaggregation modelings of hydrologic time series are efficient techniques for cases where the preservation of statistical characteristics of both annual and seasonal scales is essential for the project under study. Valencia and Schaake (1973) and later extension by Mejia and Roussell (1976) introduced the basic disaggregation model for temporal disaggregation of annual time series into seasonal time series. These models have been used extensively in modeling hydrologic time series. However, one of the drawbacks of these models is that 
they require many parameters to be estimated. Lane (1980) introduced a condensed model for temporal disaggregation model that reduces the number parameters required drastically.

The objective of this study is to investigate the use of seasonal stochastic models in modeling and simulation of rainfall in arid and semi-arid regions. In this study, two models will be used in this study. A seasonal ARMA (PARMA) model and temporal disaggregation models. The analysis will be conducted for a single site of monthly rainfall in Saudi Arabia. A regional analysis (multi-site) study will also be conducted in the near future.

\section{MATERIALS AND METHODS}

\subsection{Study Area}

The historical monthly rainfall amounts in, Saudi Arabia were used in this study. The data used was for 30 years for the period of 1981 through 2010. Figure 1 and
2 shows a time series plot of the monthly and annual rainfalls at that station respectively.

\subsection{Models Used}

The Periodic Autoregressive Moving Average (PARMA) model may be written as (Salas et al., 1980):

$$
\mathrm{Y}_{v, \tau}=\sum_{\mathrm{i}=1}^{\mathrm{p}} \phi_{\mathrm{i}, \tau} \mathrm{Y}_{v, \tau-\mathrm{i}}+\mathrm{e}_{v, \tau}-\sum_{\mathrm{i}=1}^{\mathrm{q}} \theta_{\mathrm{i}, \tau} \mathrm{e}_{v, \tau-\mathrm{i}}
$$

where, $Y_{v \tau}$ represents the standardized process for year $v$ and season $\tau$, it has a mean $=0$ and variance $\sigma_{\tau}^{2}(\mathrm{Y})$ and is normally distributed; $e_{v, \tau}$ is the uncorrelated noise term with mean $=0$ and variance $\sigma_{\tau}^{2}(\mathrm{e})$ and is also normally distributed. $\phi_{1}, \ldots, \phi_{\mathrm{p}, \tau}$ are the seasonal autoregressive parameters; $\theta_{1, \tau}, \ldots \theta_{\mathrm{q}, \tau}$ are the seasonal moving average parameters. Specifically, for $\mathrm{p}=\mathrm{q}=1$, the PARMA $(1,1)$ model becomes:

$$
\mathrm{Y}_{v, \tau}=\mathrm{j}_{1, \tau} \mathrm{Y}_{v, \tau-1}+\mathrm{e}_{v, \tau}-\theta_{1, \tau} \mathrm{e}_{v, \tau-1}
$$

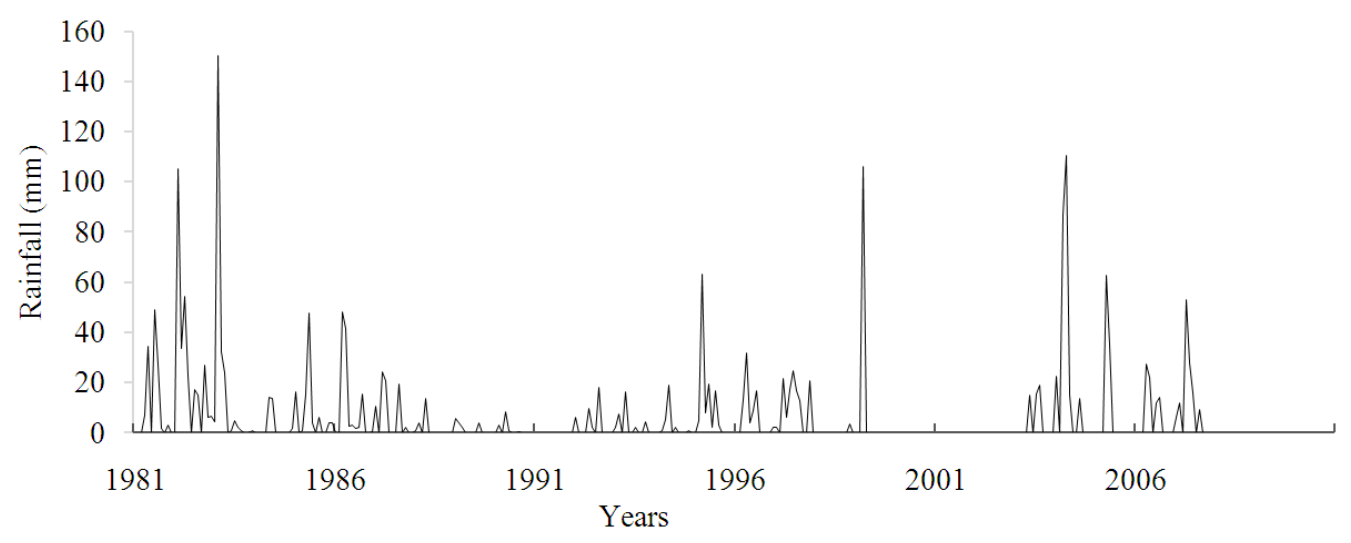

Fig. 1. Monthly rainfall in Surat Obeida, Saudi Arabia (1981-2010).

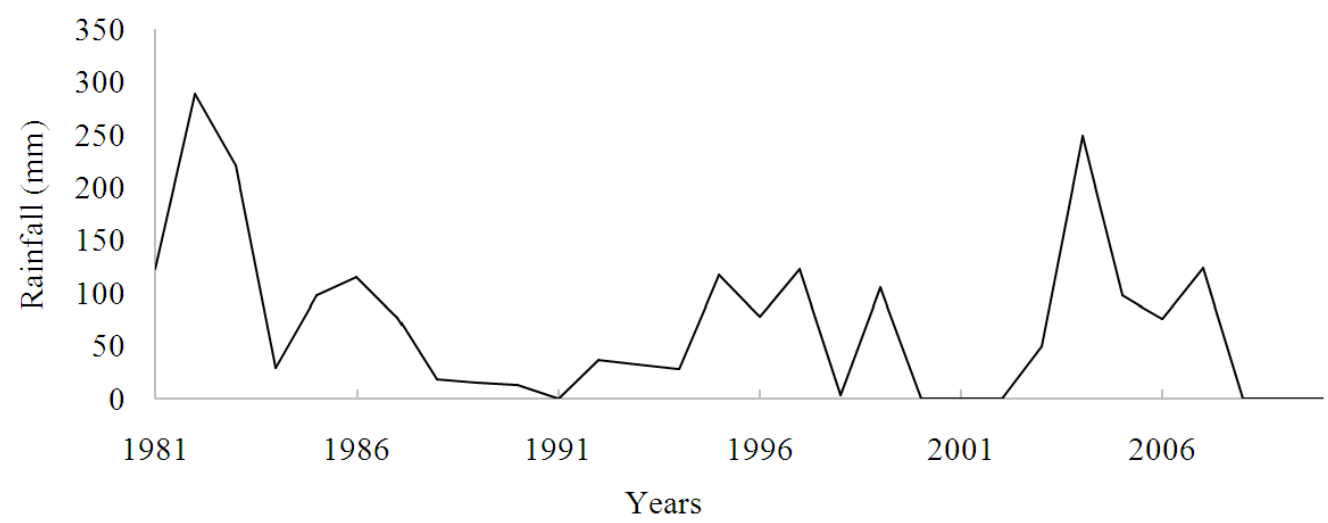

Fig. 2. Annual rainfall in Surat Obeida, Saudi Arabia (1981-2010) 
The general Lane's temporal disaggregation model for a number of sites $\mathrm{n}$ can be expressed as (Lane and Frevert, 1990):

$$
\mathrm{Y}_{v, \tau}=\mathrm{A}_{\tau} \mathrm{X}_{v}+\mathrm{B}_{\tau} \varepsilon_{v, \tau}+\mathrm{C}_{\tau} \mathrm{Y}_{v, \tau-1}
$$

In which $\mathrm{Y}_{v, \tau}$ is an $(\mathrm{nx} 1)$ column vector representing the seasonal series and $n$ is the number of sites $(n=1$ in our case). $X_{v}$ is an ( $\left.\mathrm{nx} 1\right)$ column vector representing the annual data series; $\varepsilon_{v, \tau}$ is an (nx1) vector of uncorrelated normally distributed noise term. The model parameters $\mathrm{A}, \mathrm{B}$ and $\mathrm{C}$ can be estimated using the method of moments (Lane and Frevert, 1990).

\subsection{Simulation Experiments}

Monte Carlo simulation experiments were conducted with several PARMA models with different orders as well as experiments with the Lane disaggregation model. The purpose of such experiments were to test the capability of such models to preserve the temporal correlation structure of the historical rainfall data used in this study. A software package known as Stochastic Analysis Modeling and Simulation (SAMS) was used in this study to conduct the simulation experiments (Salas et al., 2000).

To apply and use the models mentioned above, the observed data must be normally distributed. The analysis of the monthly skewness coefficients revealed that the observed data is not normal. The data was normalized by using a proper logarithmic transformation. Several PARMA models were then fitted to the normalized seasonal data. Simulation experiments were then conducted by generating synthetic time series data using the fitted models. In each experiment 100 samples, each with length of 30 years, were generated from the fitted models. The average statistics calculated from these generated series were then compared with the historical statistics.

\section{RESULTS}

\subsection{PARMA Model}

Several PARMA models were tested to model the data (in this study, only the results of the $\operatorname{PARMA}(1,0)$ are shown). The historical and generated periodic mean and periodic standard deviation using the PARMA(1,0) model are shown in Fig. 3 and 4 respectively which clearly demonstrates that the model is capable of reproducing the basic periodic statistics of the historical data. The seasonal correlation structure was also well preserved with the tested PARMA model as shown in Fig. 5. However, the model did not perform well in preserving the annual correlogram as shown in Fig. 6.

\subsection{Disaggregation Model}

Similarly, the disaggregation model also preserved the mean and standard deviation (Fig. 7 and 8). The disaggregation model also performed very well in preserving the seasonal correlation structure of the data (Fig. 9). The annual correlogram was also preserved by the disaggregation model as shown in Fig. 10.

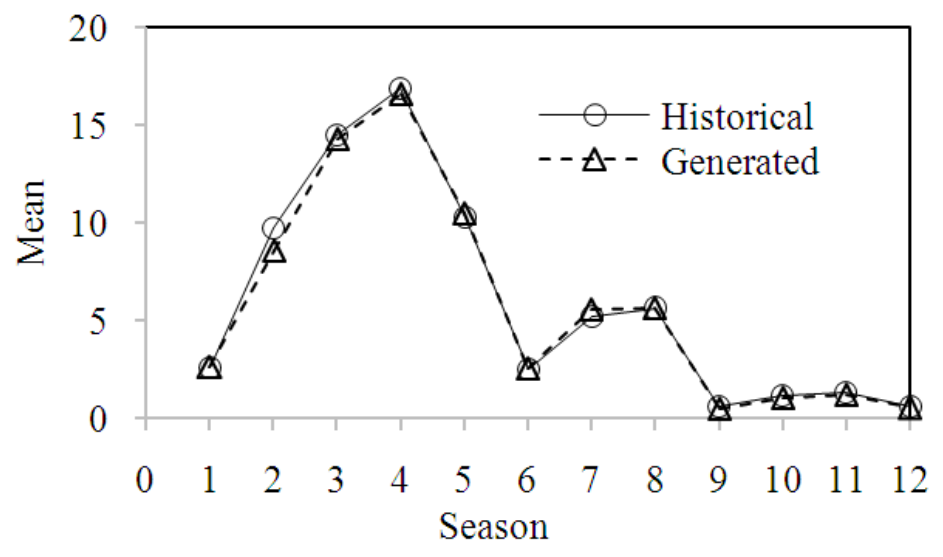

Fig. 3. Historical and generated seasonal mean for PARMA $(1,0)$ model 
Nidhal Saada / American Journal of Environmental Sciences 10 (3): 277-282, 2014

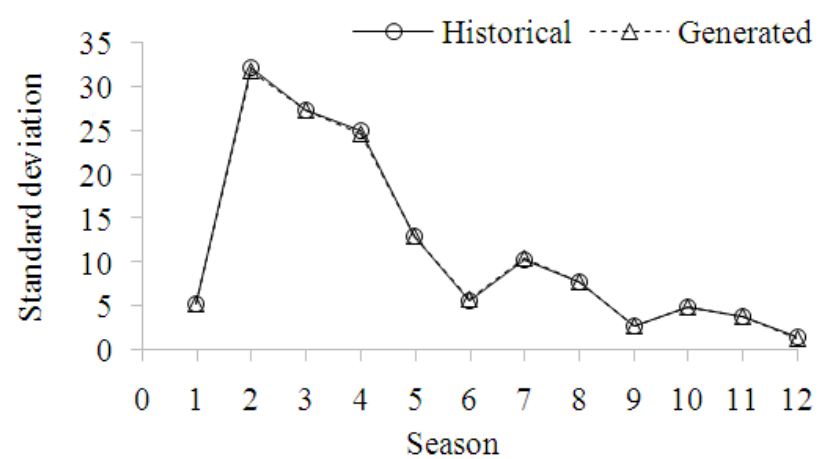

Fig. 4. Historical and generated seasonal standard deviation for PARMA(1,0) model

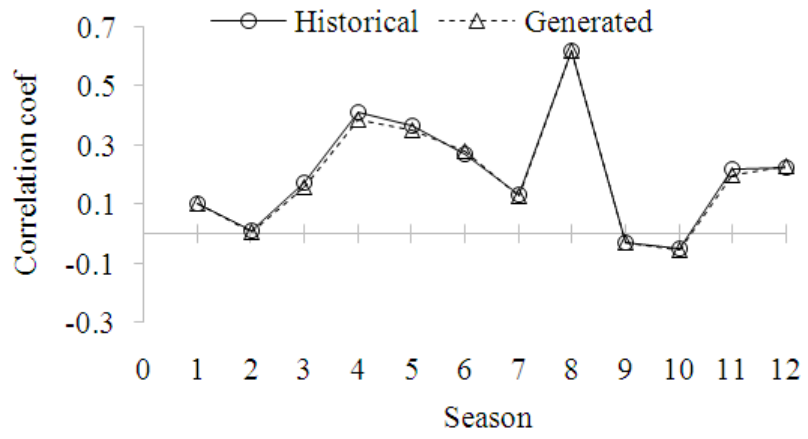

Fig. 5. Historical and generated lag-1 season to season correlation for PARMA(1,0) model

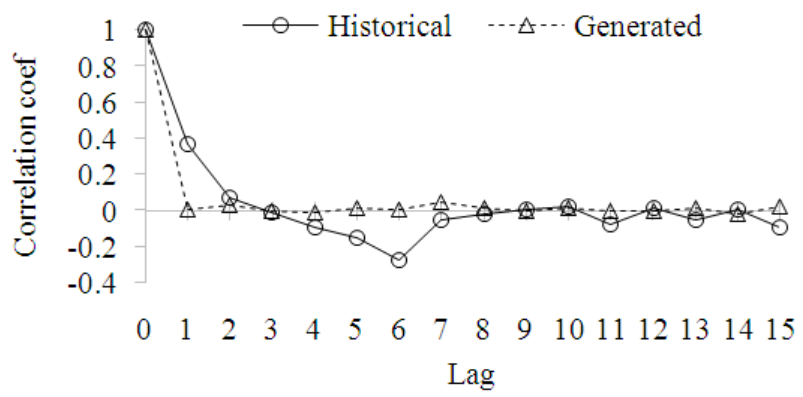

Fig. 6. Historical and generated Annual Correlogram for PRMA(1,0) model

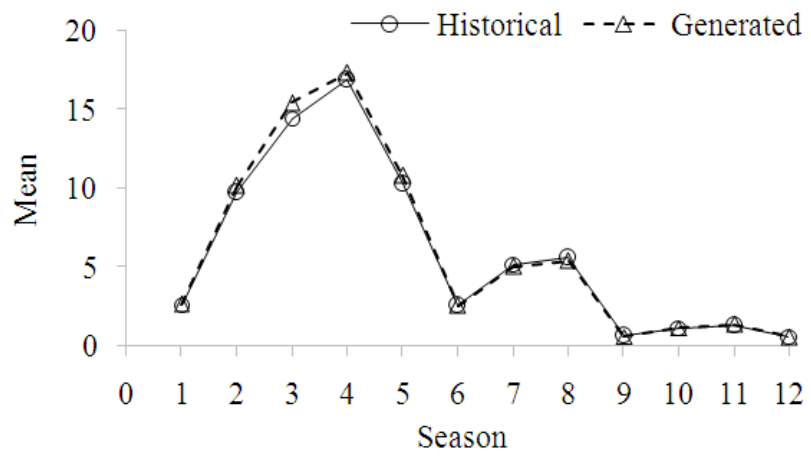

Fig. 7. Historical and generated seasonal mean for disaggregation model 


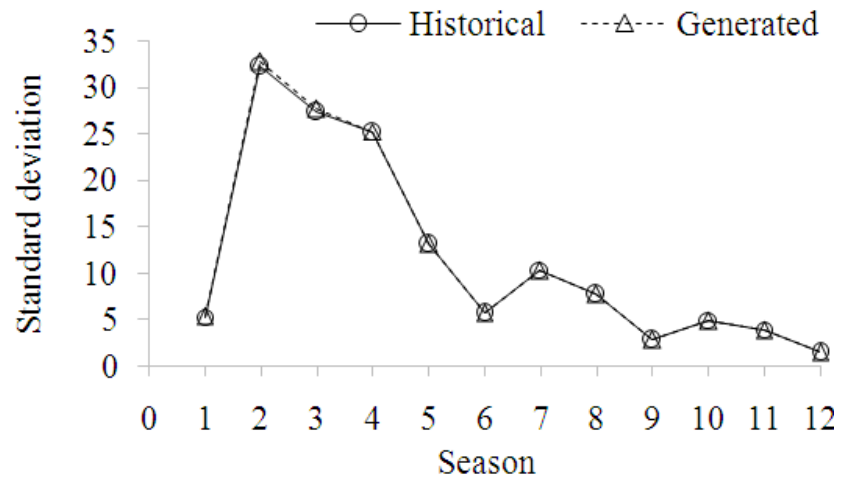

Fig. 8. Historical and generated seasonal standard deviation for disaggregation model

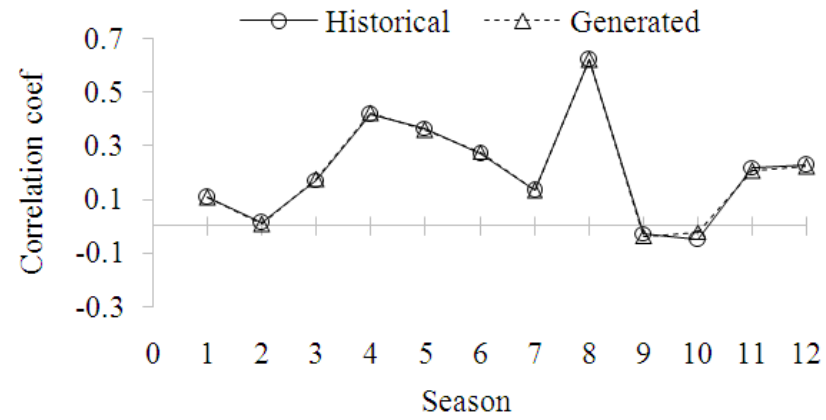

Fig. 9. Historical and generated lag-1 season to season correlation for disaggregation model

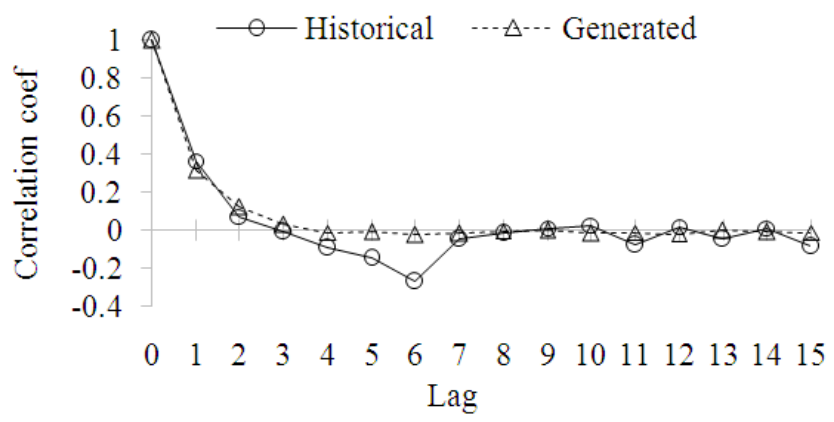

Fig. 10. Historical and generated Annual Correlogram for disaggregation model

\section{DISCUSSION}

The simulation experiments revealed that both PARMA and the disaggregation models are capable of reproducing the basic periodic statistics such as the monthly mean and the standard deviation. The seasonal correlation structure was also well preserved with the tested PARMA models. The underlying assumption of PARMA models is that they have a varying correlation structure that changes with seasons
(Salas et al., 1980). This maybe what distinguishes the PARMA models from the ARIMA models that are used in modeling monthly rainfall data. Similarly, the disaggregation model also performed very well in preserving the seasonal correlation structure of the data for the same reason as above.

One of the key features of the temporal disaggregation model is its ability to capture the correlation structure of annual time series (Lane and Frevert, 1990). In this study, the disaggregation model showed its superiority over the 
PARMA model by preserving the correlation structure of the annual data. The PARMA model was not capable of capturing the annual correlogram of the data.

It should be noted though that one of the drawbacks of periodic models (and disaggregation models as well) is that they require a high number of parameters to be estimated (Salas et al., 2000). In comparison with ARIMA models, the models used in this study required more parameters to be estimated from the data (as a result of the seasonal parameters). This would be more problematic for short time series like the data that was used in this study.

\section{CONCLUSION}

The PARMA and disaggregation stochastic models seem to be a promising tool for modeling and simulation of rainfall in arid and semi-arid regions. The PARMA and the disaggregation models were able to well preserve the seasonal statistics of the observed data. The main advantage of using these models over the widely used ARIMA models is their ability to preserve the seasonal correlation structure. However, the PARMA model was not capable of preserving the correlation structure of the annual data. On the other hand, the disaggregation model was able to preserve it. Thus, the disaggregation model was superior to the PARMA model in modeling the monthly rainfall data in Surat Obeida station in Saudi Arabia.

One limitation of this research was the fact that the data series was relatively not long (30 years). Finally, future investigation of regional (multi-site) models is needed to see if these models are able to capture the spatial dependence structure in a region in arid and semi-arid areas.

\section{ACKNOWLEDGEMENT}

The researchers would like to extend his gratitude and appreciation to Dr. Mohammed Al Zahrani, Associate Professor of Civil Engineering at King Fahd University of Petroleum and Minerals, Dhahran, Saudi Arabia for providing the historical monthly rainfall data at Surat Obeida in Saudi Arabia.

\section{REFERENCES}

Fortin, V., L. Perreault and J. Salas, 2004. Retrospective analysis and forecasting of streamflows using a shifting level model. J. Hydrol., 296: 135-163. DOI: 10.1016/j.jhydrol.2004.03.016
Kim, S., 2012. Development of Hybrid Method for the Modeling of Evaporation and Evapotranspiration. In: Evapotranspiration-Remote Sensing and Modeling, Irmak, A. (Ed.), InTech., ISBN: 978-953307-808-3, pp: 351-376.

Lane, W.L., 1980. Applied Stochastic Techniques Last Computer Package: User Manual. Ist Edn., Division of Planning Technical Services, Denver, Colo.

Lane, W.L. and D.K. Frevert, 1990. Applied Stochastic Techniques: Personal Computer Version: User Manual. 1st Edn., Earth Sciences Division, Denver, Colo, pp: 92.

Mejia, J.M. and J. Rousselle, 1976. Disaggregation Models in hydrology revisited. Water Resources Res., 12: 185-186. DOI: 10.1029/WR012i002p00185

Naill, P.E. and M. Momani, 2009. Time series analysis model for rainfall data in Jordan: Case study for using time series analysis. Am. J. Environ. Sci., 5: 599-604. DOI: 10.3844/ajessp.2009.599.604

Salas, J.D., J.W. Delleur, V. Yevjevich and W.L. Lane, 1980. Applied Modeling of Hydrologic Time Series. 1st Edn., Water Resources Publication, Littleton, Colorado, ISBN-10: 0918334373, pp: 484.

Salas, J.D., D.C. Boes and R.A Smith, 1982. Estimation of ARMA models with seasonal parameters. Water Resources Res., 18: 1006-1010. DOI: 10.1029/WR018i004p01006

Salas, J.D., N. Saada and C.H. Chung, 1995. Stochastic modeling and simulation of the Nile River system monthlyflows. Computing Hydrology Laboratory, Colorado State University.

Salas, J.D., N. Saada, C.H. Chung, W.L. Lane and D.K. Frevert, 2000. Stochastic Analysis, Modeling and Simulation (SAMS) version 2000-user's manual. Colorado State University.

Shao, Q., H. Wong, M. Li and W.C. Ip, 2009. Streamflow forecasting using functional-coefficient time series model with periodic variation. J. Hydrol., 368: 88-95. DOI: 10.1016/j.jhydrol.2009.01.029

Valencia, R.D. and J.C. Schaake, 1973. Disaggregation processes in stochastic hydrology. Water Resources Res., 9: 580-585. DOI: 10.1029/WR009i003p00580

Sampson, W., N. Suleman and Gifty, 2013. Proposed seasonal autoregressive integrated moving average model for forecasting rainfall pattern in the Navrongo municipality, Ghana. J. Environ. Earth Sci., 3: 80-85. 